\title{
Uma proposta didática a partir de Bertolt Brecht
}

Rita Alves Miranda

Mestranda em Filosofia na PUC-SP

\section{Resumo}

Este texto compreende uma proposta educativa baseada no processo didático para o teatro concebido pelo dramaturgo e teórico alemão Bertolt Brecht, proposta essa que tenta, através do uso da peça Vida de Galileu, uma das mais importantes do autor, promover com alunos de Ensino Médio um processo semelhante ao desenvolvido pelo teatrólogo com seus atores. Acrescenta-se a isso a ação da reflexão filosófica para pensar os temas discutidos na peça, como o advento do conhecimento científico e as consequências dele para a formação do novo homem, regido agora pelas vias do pensamento racional.

Palavras-chave: Teatro; Educação; Filosofia.

\begin{abstract}
This text develops an educational proposal based on the didactic process for the theater thought by the German dramatist and theorist Bertolt Brecht, proposal that attempts, through the use of the play Galilleo's Life - one of the Brecht's most important plays - to develop amongst high school students a process similar to the one fulfilled by the author with his actors. One must add to that the philosophical reflection used to think the themes discussed in the play, as the advent of scientific knowledge and the its consequences to the formation of a new man, lead now by the paths of rational thinking.
\end{abstract}

Keywords: Theatre; Education; Philosophy. 


\author{
A canalização de um rio \\ O enxerto de uma árvore \\ A educação de uma pessoa \\ A transformação de um Estado \\ Estes são exemplos de crítica frutifera. \\ E são também \\ Exemplos de arte.
}

Bertolt Brecht

ostuma-se dizer que, mais importante que o resultado de uma montagem teatral para os atores, é o processo de trabalho e tudo aquilo realizado nele. Com o presente texto pretendemos unir num método de pesquisa, portanto de descobrimento - pensando na educação de um indivíduo, fillho desta era -, dois campos do conhecimento humano: o Teatro e a Filosofia.

Embora inicialmente se tratando de uma escolha bastante pessoal ${ }^{1}$, percebemos cada vez mais, com a observação e o estudo das práticas de ensino, assim como a vivência de alguns tipos dessas práticas, a possibilidade dessa conversa entre Filosofia e Teatro, principalmente quando dirigida a um processo de aprendizado. Há entre esses dois campos uma espécie de elo preestabelecido, que é o ponto de encontro deste projeto.

Para guia dessa pesquisa teórica escolhemos o dramaturgo Bertolt Brecht, que ao longo de sua vida, principalmente quando desenvolveu o Teatro Épico, preocupou-se também em dar continuidade ao desenvolvimento do Teatro didático, cujo caminho mais conceitual do que prático - já vinha sendo traçado por um de seus mestres neste campo, Erwin Piscator. Diz-se que Brecht se dedicou durante muito tempo, no teatro, antes de qualquer coisa, à pedagogia. Sofreu, assim, muitas críticas em relação a essa postura porque, durante certo período, essa preocupação acabou afastando-o do objetivo primordial do teatro, que sempre foi, afinal, o de divertir sua plateia.

1Este texto foi desenvolvido inicialmente como Trabalho de Conclusão de Curso (TCC) de licenciatura em Filosofia, na PUC-SP. Trata-se de uma experimentação teórica que se utilizou de conceitos e discussões sobre práticas possíveis para o ensino de Filosofia e a formação de indivíduos, em conjunto com um interesse pessoal pela proposta teatral de Bertolt Brecht. 
Quanto a isso, a inovação deixada por Brecht também estará presente no projeto de mesclar Filosofia, Teatro e educação. Brecht quis romper com a ideia de que existe uma diferença abismal entre aprender e divertir-se e que vem sendo saturada pela tradição. Essa oposição, segundo ele, não teria que ser necessária.

Influenciado pelos ideais marxistas, acreditava que somos acostumados a um tipo de instrução e que essa, como quase tudo em nossa sociedade, tornou-se mercadoria e, portanto, delimita poder. Aquele que quer aprender, primeiro deve admitir que não sabe e precisa, em contrapartida, eleger alguém que saiba mais que ele, ou seja, alguém que é detentor de sabedoria: um mestre. É então que rebate aquele ponto de vista, elevando o teatro a um modo de instrução que causa prazer e ao mesmo tempo ensina. É a esse ponto que o presente trabalho se dirige. Segundo ele:

O palco passou a ter uma ação didática.

O petróleo, a inflação, a guerra, as lutas sociais, a família, a religião, o trigo, o comércio de gado de consumo passaram a fazer parte dos temas de teatro. Coros elucidavam o espectador acerca dos fatos para ele desconhecidos. [...] O teatro passou a oferecer aos filósofos uma excelente oportunidade, oportunidade, aliás, aberta apenas a todos aqueles que desejavam não só explicar como também modificar o mundo. Faziase filosofia; ensinava-se, portanto. E, com tudo isto, o teatro perdia a sua função de entretenimento? Acaso nos empurravam de novo para os bancos da escola e nos tratavam como analfabetos? Queriam que fizéssemos exames, que conseguíssemos um diploma? (BRECHT, 2005, p.67)

Para objetivar melhor a exposição da proposta e as diretrizes a serem seguidas, é preciso ter claro que ela não foi pensada para ser vivida por atores, mas para servir a alunos de Ensino Médio, no trabalho destinado à matéria de Filosofia, ou a escolas que tenham projetos paralelos, de teatro e interdisciplinaridade. $\mathrm{O}$ importante é que o projeto seja realizado por uma turma com a qual se possa desenvolver um processo de um ano, com aulas semanais de duas a três horas cada. Se houver mais tempo disponível, melhor.

Se a peça didática foi concebida por Brecht com o objetivo de interferir na organização da sociedade, naquilo que diz respeito aos trabalhos em grupo, o projeto de trabalhar peças de teatro com os alunos na aula de Filosofia, e neste caso 
especificamente com Vida de Galileu - embora esta não sido classificada como didática pelo autor -, tem por objetivo interferir diretamente no método habitual de ensino, pretendendo modificar essa visão comum que toma como verdadeira a oposição entre aprender e divertir-se. Essa modificação se dá como pretendia Brecht na relação entre os atores em atividade e os espectadores em sua passividade, ou seja, entre quem ensina e quem aprende. Os alunos, no caso, serão tanto espectadores quanto atores.

Há muitos modos de diversão a serem explorados, e muitas vezes eles estão presentes nos momentos mais simples da vida. É necessário que se descubra antes o que cabe e o que não cabe ser usado no trabalho. As coisas do dia-a-dia são trazidas de forma distanciada do cotidiano, o que permite que não haja identificação e que se perceba o que está acontecendo, provocando interesse em quem assiste e faz a cena. Assim, cada processo será diferente e cada grupo, em compasso com o professor (que será uma espécie de autor-narrador da peça), escolherá a melhor forma de aprender com ele e suas possibilidades.

Dessa forma, se teatro é diversão e aprender tem que ser divertido, e se aprender deve partir primeiro de uma reflexão, de um pensamento, a Filosofia também está presente. O que se pode concluir previamente disso é que Filosofia e Teatro, para um projeto educacional, não poderiam constituir uma união melhor. Além disso, são ambas as disciplinas passíveis de um conteúdo flexível. Não devem ser exploradas como outras matérias que se apoiam no aprender por fixação, por repetições.

No livro Brecht: um jogo de aprendizagem, Ingrid Dormien Koudela, professora da USP que realizou algumas experiências de aprendizagem recorrendo à obra de Brecht, expõe um trecho de um texto dele, "Compra do Latão", que é bastante interessante para a proposta de se trabalhar Filosofia com Teatro:

O dramaturgo indaga:

- E como se aprende, a partir da experiência? Pois no teatro não se vê apenas, mas também se experimenta. Existe melhor forma de aprendizagem?

Ao que o filósofo responde:

- Aí devemos examinar como se aprende através da experiência, sem que elementos de comentário sejam introduzidos. Existem muitos momentos, que impedem o aprender e/ou o tornar-se mais esperto ao experimentar. Por exemplo, quando 
determinadas mudanças da situação se processam de forma demasiado lenta, imperceptivelmente, como se costuma dizer. Ou, quando, através de incidentes, a atenção é dispersada. Ou quando se buscam as causas em acontecimentos que não eram causa. Ou quando aquele que experimenta tem fortes preconceitos.

DRAMATURGO: Ele não pode abandonar seus preconceitos através de determinadas experiências?

FILÓSOFO: Só se tiver refletido. Mesmo assim, ainda pode esbarrar em obstáculos.

DRAMATURGO: Mas então 'fazer por si mesmo' não é a melhor escola?

FILÓSOFO: A experiência que é transmitida através do teatro não é um fazer por si mesmo. É errado acreditar que toda a experiência é um experimento e querer retirar da experiência todas as vantagens que tem um experimento. Há uma enorme diferença entre uma experiência e um experimento. (KOUDELA, 2007, p.24)

Posto isso, o que esperamos como experimento não necessariamente se tornará experiência de palco, resultado. No entanto, pretende-se neste projeto que se trate de um experimento cauteloso e que vise à reflexão própria de cada um dos alunos, para que haja aprendizado, que não está relacionado aos produtos usuais do sistema educacional comum. Resta esperar que os alunos sejam cativados e que se disponham a saírem do "sono profundo", o que pode provocar - e assim se deseja -, como nos gregos, uma espécie de admiração com estranhamento, mas que no caso, não será ela familiar. Espera-se que seja diferente e suscite mudanças. Como disse Alejandro Cerletti:

Os professores de filosofia ocupam o difícil lugar da transmissão, da provocação e do convite. Transmitem saberes, mas provocando o pensamento e convidando a pensar. Difundem certos conhecimentos, mas promovem sua apropriação pessoal. Tentam mostrar, em definitivo, que sobre toda a repetição é imprescindível que o filosofo sobrevoe o terreno dos saberes aceitos fixando o olhar agudo em cada um de eles, para interrogá-los e interrogar-se. Nisso radica sua atitude. (CERLETTI, 2009, p. 39)

\section{Processo didático entre Filosofia e Teatro}

Esta é uma proposta teórica que tem por objetivo central a união entre duas disciplinas que lidam com o mundo subjetivo de cada aluno. Ao mesmo tempo - pensando na atividade de filosofar, de um lado, como algo racional que envolve a atividade de pensar, e de outro o Teatro, que permite também um pensar, mas que deve ser prévio à ação porque durante ela só se aceita o fazer - podemos dizer que estamos lidando com 
disciplinas opostas. É dessa oposição, contudo, que se esperam grandes acontecimentos. Esperamos que ambas se completem. Para isso, será necessário que a mente e o corpo dos alunos estejam presentes o tempo todo, o que nos transporta a um desafio ainda maior: o de cativá-los, trazendo-os para o universo desse processo.

Por seu caráter ainda teórico, trata-se de um plano de experimento que está aberto a modificações. Para elaborá-lo, partimos das concepções de ensino de Filosofia que acreditam na liberdade desse ensino, que não estabelecem um sistema fechado, ou algo que contribua para limitar a capacidade criativa e intelectual dos alunos. Apresentamos uma proposta teórica que não exclui mudanças na prática e que aceita fazê-las mediante o conhecimento do grupo com o qual deverá ser desenvolvido o trabalho. Brecht queria usar o Teatro como meio didático e de comunicação. Queremos, com esse processo, dar continuidade ao seu desejo fazendo do Teatro um meio didático de comunicação com a Filosofia.

A transformação do teatro em pedagogia propõe que, através de meios teatrais, é possível estudar e elaborar experiências individuais e históricas que se instauram nas disposições e atitudes corporais e determinam o comportamento. (KOUDELA, 2009, p.98)

Sabemos, contudo, que num mesmo grupo há sempre diferenças entre seus integrantes, principalmente quando se lida com jovens que enfrentam uma fase de profundo crescimento intelectual, emocional, na descoberta de suas personalidades. Dessa forma, será fundamental trabalhar com esses alunos a integração entre eles, como também o respeito que terão que ter um pelo outro. Isso faz parte da postura que se pretende desenvolver no processo didático. Para Alejandro Cerletti:

Ainda que se possa criar as condições para um encontro amoroso com o saber (pode-se convidar a pensar), os encontros sempre têm algo de aleatório. Como dissemos, há um distância impossível de preencher com os saberes do professor, na qual se joga a novidade do outro, sua própria relação com a filosofia. Pensar implica novidade e isso tem sempre algo de inquietante porque escapa ao controle da simples transmissão de um saber. É inquietante para o professor, porque o afasta de um caminho já trilhado da transmissão de conhecimentos e o leva a enfrentar o desafio de pensar ele mesmo. (CERLETTI, 2009, p.38) 
É evidente que um trabalho como esse, que tem relação com o comportamento de cada indivíduo num grupo, não finda na elaboração de um projeto e sim com o trabalho constante, paralelo às educações familiar e escolar - embora, em ambas, não nos seja possível exercer nenhum tipo de controle ou influência direta. Como há metas a serem conquistadas e é preciso ter cautela, nos preocuparemos, por ora, apenas com a função teórica que compete a este trabalho. Do contrário, estaríamos assumindo o risco de discutir um problema que já é frequentemente penoso para a educação e que nasce quando ela assume essa responsabilidade - que acabou sendo transportada muitas vezes também para a disciplina de Filosofia - de dar conta de questões de moral e ética, responsáveis pela formação do indivíduo enquanto sujeito social, sendo que acreditamos que essa competência não cabe a uma só disciplina. Tal responsabilidade deveria ser de todas as áreas, da sociedade e do Estado.

\subsection{0 processo}

No que se refere às aulas, ao desenvolvermos uma espécie de plano para a abordagem do texto escolhido, juntamente com possibilidades de práticas, notamos que para Brecht, no processo didático, é importante que a técnica de distanciamento esteja sempre presente. Os alunos têm que aprender a pensar sobre suas ações e a retratá-las como acontecimentos pelos quais passaram, o que permitiria uma distância na hora de se pensar - como quando acontece algo perturbador em nossa vida, algo a respeito do qual, no momento em que acontece, não conseguimos pensar, mas que no dia seguinte parece se mostrar a nós com mais clareza -, quando há uma reflexão consciente dos fatos. Dessa forma, assinalamos mais uma vez que é pertinente a escolha da peça Vida de Galileu para esse processo, uma vez que, como acontecimento histórico, não se relaciona diretamente com a experiência dos alunos, mas transmite uma distância ainda maior. Lembre-se também que Vida de Galileu é uma interpretação dos acontecimentos feita por Brecht, uma biografia que poderia muito bem ser contada por nós de outra forma. 
Também o estranhamento deverá ser utilizado pelos alunos em suas investigações práticas. A interpretação livre, experimentada por amadores, demanda a possibilidade ao aluno de entrar e sair do papel mais vezes que num processo teatral normal, favorecendo o estranhamento e um "não envolver-se" (emocionalmente) de forma total, pelo estudante. É claro que, mesmo assim, teremos que lidar com o aspecto subjetivo dos sentimentos.

O aluno é livre na hora de sua participação cênica para emprestar aspectos seus ao papel. Isso poderá ser comentado por ele e, porque não?, levado a uma discussão em sala das escolhas feitas por ele e por cada um, tendo por base o que havia sido discutido anteriormente, fora de cena. Os sentimentos podem, sim, gerar reflexões riquíssimas. Por exercícios e jogos teatrais, tomaremos também as imitações e as improvisações, como as desenvolvidas por Augusto Boal e seu Teatro do Oprimidoº

Ainda assim, o foco do processo é o de, através da análise textual e do levantamento e compreensão de questões, promover posteriormente a isso uma ação prática. Pretende-se que haja espaço para a Filosofia e para o Teatro respeitando a individualidade de cada um desses dois campos. Desse experimento, espera-se que nasça uma atitude mais consciente por parte dos alunos na conjuntura de determinados conteúdos. Por ser um trabalho cujo programa tem certa abertura, há a possibilidade de referências como: vídeos, músicas, poemas ou outros textos; desde que tornem mais ricas as discussões e que tenham pontos em comum com o restante, deverão ser utilizados. Tanto como sugestão do professor, quanto dos alunos, é importante dar valor ao trabalho mútuo, porque isso também pode servir de estímulo para ambos.

A peça escolhida, Vida de Galileu, além de ser trabalhada pela Filosofia, abre campo para a discussão interdisciplinar, como com as disciplinas Física e História. A partir disso, o assunto poderia se estender, o que seria muito interessante para os alunos

2 Augusto Boal desenvolveu o Teatro do Oprimido, que teve influência do Teatro didático de Brecht, um teatro para atores e para aqueles que não são atores. Para ele: "Todo mundo atua, age, interpreta. Somos todos atores. Até mesmo os atores! Teatro é algo que existe dentro de cada ser humano, e pode ser praticado na solidão de um elevador, em frente um espelho, no Maracanã ou em praça pública para milhares de espectadores. Em qualquer lugar... até mesmo dentro dos teatros." (BOAL, 2002, p. ix) No livro Jogos para a atores e não-atores, desenvolve exercícios e técnicas desse teatro que rodou o mundo todo. Os exercícios presentes nesse livro devem ser utilizados nas aulas. 
e para a escola. Cada um poderia dar a sua contribuição, e isso envolveria um número maior de participantes, seja direta, seja indiretamente.

O texto é o ponto de partida para possíveis abstrações e reflexões que associam ideias, umas às outras. Embora esteja permeado de referências, que podem dar o aspecto de restrição, é importante que algumas questões levantadas estejam relacionadas à vida do aluno. Isso possivelmente trará uma aproximação maior por parte deles, para com o trabalho. As associações com o cotidiano devem ser exploradas tanto nos seus conteúdos teóricos quanto pelas possibilidades que podem trazer para a experiência prática das cenas sobre essa realidade. Os alunos podem pensar em questões como as relacionadas à situação de injustiça a que Galileu é submetido. Esse tipo de situação acontece diariamente e isso pode ser explorado. Para facilitar esse tipo de abordagem é importante lidar com improvisações de pequenos trechos de texto.

Tendo em vista que para Brecht é fundamental a situação do espectador no processo didático, que tem como centro o coletivo, os atores (amadores) são espectadores de si mesmos e de seus colegas. Ou seja, todos devem se assistir. Todavia, não deve haver uma grande preocupação com o modo de atuar porque o processo visa ao desenvolvimento de uma atitude politizada e tem como base, justamente, os indivíduos no cotidiano. Tendo em vista que este é um trabalho para ser desenvolvido com alunos de Ensino Médio, eles deverão escolher até que ponto gostariam de se envolver na experiência teatral.

O trabalho e a avaliação dos alunos devem ser feitos em vista da doação de cada um como indivíduo pensante e membro do grupo, assim como da sociedade e do trabalho que cada um empreendeu em prol do coletivo - o que podemos chamar também de disposição e generosidade. Como é um trabalho bastante livre, outro tipo de avaliação talvez não fosse justo. Nesse ponto, e em alguns outros, tomamos como inspiração a proposta de avaliação de Cerletti. Ele fala de uma espécie de auto-avaliação realizada pelo aluno:

$\mathrm{Na}$ avaliação que corresponde à educação formal, sempre é outro quem decide, em última instância, quando alguém aprendeu. [...] No caso da filosofia, a questão é 
complexa porque, como sustentamos, no desejo de filosofar, ou na irrupção de um pensar, se joga a originalidade de cada um. Isso só quem começa a filosofar, por mais modesto que seja esse filosofar, estaria em condições de afirmar que 'aprendeu' a filosofar. Porque esse vínculo com o saber é singular e irredutível. Não é possível julgar esse amar ou desejar o saber. Claro está, como indicamos, o que um professor pode fazer - e de fato é o que faz em qualquer exame- é constatar a posse de alguma informação sobre a historia da filosofia ou a aquisição de algumas habilidades argumentativas. Mas, num sentido estrito, só quem 'aprende' filosofia poderia dizer 'aprendi'. Só ele poderia ser a medida real de sua aprendizagem filosófica, já que qualquer mudança real supõe uma transformação subjetiva. (CERLETTI, 2009, p.84)

Espera-se, assim, desenvolver um exercício dialético entre teoria e prática. Pensou-se na possibilidade de o grupo desenvolver a própria linguagem estética, mas isso seria definido por último. De qualquer forma, desde o começo acredita-se que aquilo que se configura como uma espécie de "personalidade" do grupo vá aparecendo naturalmente. Mais uma vez, é importante ressaltar que este é um projeto de ensino e por isso está aberto a mudanças. O que foi feito, a partir desta explicitação de uma possibilidade para a prática, foi apenas obter certa dimensão a nível teórico. A proposta baseia-se na seguinte conclusão:

Atuar é ser espectador de si próprio. A peça didática ensina quando a gente é atuante e, ao mesmo tempo, espectador dos próprios atos. Influenciar socialmente é assumir determinadas atitudes, realizar determinadas ações e repetir (citar) determinadas falas. $\mathrm{O}$ ato coletivo realiza-se por meio da imitação e crítica de modelo de comportamento, atitudes e discursos. Ensinar/aprender é gerar uma atitude crítica e um comportamento político. (KOUDELA, 2007, p.164)

\subsection{A escolha da peça Vida de Galileu}

A partir dos textos de Ingrid Koudela sobre o Teatro didático e suas experimentações práticas, observamos que há uma preferência por um processo didático, por peças que dispõem de certa abstração, com a intenção de que a atitude política nasça a partir do movimento de decisão e abstrações por parte dos experimentadores. Para Ingrid Koudela, é pouco possível que isso aconteça com peças que têm uma realidade específica, ou que têm como tema fatos históricos. 
Não obstante, sem pretensões de contrariar essa visão - mesmo porque nos utilizamos muito de suas pesquisas neste trabalho -, a Filosofia, em nosso caminho, por ter como sua qualidade específica para reflexão o texto, nos levou a escolher outro tipo de peça, como é o caso de Vida de Galileu. Acreditamos, sim, ser possível que do estudo dessa peça possam provir discussões muito válidas, reflexões teóricas intensas e, dentro desses problemas, porque não?, experimentos práticos riquíssimos.

Essa peça de Brecht não se configura no núcleo das peças didáticas do autor, mas como o processo aqui defendido também se distancia um pouco daquele concebido para ser um processo didático, torna-se possível a sua utilização. O que nos interessa é desenvolver uma atividade que, por sua vez, impulsione a descoberta de uma postura. Será o desenvolvimento dessa postura o alvo deste projeto de investigação. Sendo assim, não deixará de ser um processo genuinamente didático e muitas características e técnicas da concepção de Brecht deverão ser experimentadas com a peça, apesar de sua classificação. Pois, segundo ele mesmo, esse não é um evento para “quaisquer" pessoas e o que será levado em conta como feedback são os próprios alunos e suas opiniões.

Há uma grande mudança no pensamento, que é identificada nessa peça e nos que levou a escolhê-la. A peça fala de Galileu, na visão de Brecht, na época em que suas ideias começaram a ter repercussão e causar desconforto a algumas partes da sociedade. Além disso, tornaram-se ameaçadoras para aqueles que detinham o conhecimento. Galileu é apaixonado pelo conhecimento e, por ensinar, tem como seu aluno o menino Andrea, filho da governanta de sua casa, que adora aprender com o mestre. No entanto, as coisas começam a ficar difíceis para Galileu, como consequência da perseguição por parte da Inquisição e de suas aulas particulares não serem suficientes para a própria sobrevivência. Logo no começo o personagem Galileu mostra-se adepto da mudança:

Muros e cascas, tudo parado! Há dois mil anos a humanidade acredita que o Sol e as estrelas do céu giram em torno dela. O papa, os cardeais, os príncipes, os sábios, capitães, comerciantes, peixeiras e crianças de escola, todos achando que estão imóveis nessa bola de cristal. Mas agora nós vamos sair, acabou e começou um tempo novo. Já fez cem anos que a humanidade está esperando alguma coisa. As cidades são estreitas, e as cabeças também. Superstição e peste. Mas veja o que se diz agora: se as coisas são assim, assim não ficam. Tudo se move, meu amigo. [...] E surgiu um grande gosto pela 
pesquisa da causa de todas as coisas: saber por que cai a pedra, se a soltamos, e como ela sobe, se a jogamos para cima. Não há dia em que não se descubra alguma coisa. (BRECHT, 1999, p.57)

No trecho acima já podemos ver diversas questões que podem ser discutidas. Galileu dá uma aula sobre um momento pelo qual o conhecimento humano passou. Ele foi um dos primeiros talvez a romper com as concepções antigas de ciência, trazendo à tona, ao mesmo tempo, uma nova concepção de mundo. A peça mostra de forma marcada a divisão entre dois mundos: o antigo e o novo. Galileu vem do mundo antigo e quer ir para o novo porque aquele em que ele está não o provoca mais a dar continuidade a seus estudos e assim, evoluir em seu conhecimento. Nessa tentativa, de adentrar em algo inevitável, que são os indícios do que mais tarde virá a ser um mundo moderno - e do qual não se fazia ideia do que seria -, há um embate e Galileu é impedido de continuar por aqueles que temiam suas descobertas e o que elas carregavam de novidade.

Suas descobertas confirmaram uma inquietação que é do homem com sua sede de conhecer: o seu desejo de saber e de estabelecer uma nova relação com o mundo. Inquietação essa que é capaz de trazer a sua evolução, assim como sua desgraça. O clima, já desde o início da peça, é de tensão, e isso vai se agravando com a investida de Galileu em tentar provar a validade de suas descobertas. Ele mostra-se inconformado desde o início e tem fé na razão humana, acreditando que diante de suas provas os membros da Igreja se redimiriam e ficariam impressionados e o apoiariam. Ele acredita nisso.

Ora, já temos aqui algumas questões que poderiam ser discutidas em sala de aula. Para melhor exposição e abordagem do tema, selecionamos algumas:

- A fé de Galileu, que no começo do texto lhe dava força e que depois, com as tormentas passadas ao longo da peça podemos vê-la transformando-se em conformação, em descrença. Teria ele perdido a fé na razão humana?

Galileu - [...] Veja aqui, Sagredo! Eu acredito no homem, e isto quer dizer que acredito na sua razão! Sem esta fé eu não teria força de sair da cama pela manhã. (BRECHT, 1999, p.80) 
- $\quad$ A Igreja não podia crer que, com a descoberta de Galileu, o céu objeto de devoção de toda a fé, poderia perder seu valor de morada do Divino. Como aparece no texto: "Dez de janeiro de mil seiscentos e dez: Galileu Galilei via que o céu não existia." (BRECHT, 1999, p.73) Como poderia ser a terra só mais uma estrela? Depois de séculos de conquista pela Igreja, influenciando as pessoas, reunindo adeptos, criando leis morais, como poderia não ser mais ela a grande detentora de todo conhecimento? Que implicações essa mudança trouxe para a humanidade? Na peça, o Cardeal diz:

Nós atribuímos a um Ser Supremo a responsabilidade pelo sentido desses fatos que não logramos compreender e que constituem a vida- dissemos que havia uma certa finalidade nessas coisas, que isso tudo obedecia a um grande plano. Ainda assim, o sossego nunca foi completo; e agora vem o senhor e diz que o Ser Supremo entendeu mal o movimento dos céus, que o senhor entendeu bem. Isso é prudente? (BRECHT, 1999, p.113)

- Galileu é julgado pela Inquisição, e para não morrer abre mão da verdade. Tal situação pode ser relacionada com o cotidiano, em que muitas pessoas têm de abdicar de alguma verdade, ou simplesmente daquilo em que acreditam, porque essa é a vontade dos outros a quem eles, por sua vez, obedecem socialmente. Até que ponto vai esse "ter de"? Será que Galileu não poderia ter tomado outra decisão? Essa teria sido a melhor escolha? De que modo nossas escolhas podem interferir no mundo e em nossas vidas? Brecht parece ir mais longe ao mostrar outra saída no final da peça: Galileu não abandona totalmente a ciência, seu amor é maior; ele acha um meio para remediar o que parecia irremediável. Esse é o exemplo da aposta de Brecht na mudança. Essa mensagem é de suma importância porque ela é ponto chave para despertar a motivação do amor à ciência, do amor ao saber.

- $\quad$ Esse amor é o mesmo que faz com que Andrea, aluno de Galileu, se apaixone pela ciência e queira ser físico. O entusiasmo de seu mestre acaba transformando sua motivação. Nasce nele o interesse pelo conhecimento.

- Um contraponto que pode ser feito com a questão anterior e com o cotidiano é o aparecimento do personagem Ludovico, que nada entende de 
ciência mas é obrigado a frequentar as aulas. Admira Galileu, mas se interessa por outras coisas, como cavalos. Há um valor em questão, que naquela época era atribuído a quem estudava. E, no entanto, Galileu já era mal remunerado como professor. Que valor é esse? Não estaria ele ligado a um mundo de aparências, onde a erudição é status? Isso existe nos dias de hoje? De que forma?

- A demonstração feita por Galileu do novo sistema copernicano é muito interessante e poderia ser trabalhada com a disciplina de Física. Os alunos poderiam experimentar a cena em que Galileu explica para Andrea esse novo sistema. Durante muito tempo o homem achou que o sol se movia e a Terra não. Descobre-se que a Terra se move. Como é para os habitantes da Terra essa questão?

- $\quad$ A discussão da ciência e a sua validade podem ser exploradas também. Galileu diz:

Mesmo a doutrina do grande Copérnico ainda não está provada. Ela é apenas uma hipótese. [...]

Andrea - O que é uma hipótese?

Galileu - É quando uma coisa nos parece provável, sem que tenhamos os fatos. Veja a Felícia, lá embaixo, na frente do cesteiro, com a criança no peito. É uma hipótese que ela dê leite à criança e que não seja o contrário; é uma hipótese enquanto eu não puder ir lá, ver de perto e demonstrar. Diante das estrelas, nós somos como vermes de olhos turvos, que veem muito pouco. As velhas doutrinas, aceitas durante mil anos, estão condenadas; há mais madeira na escora do que no prédio enorme que ela sustenta. Muitas leis explicam pouco, enquanto a hipótese nova tem poucas leis que explicam muito. (BRECHT, 1999, p. 69)

Há muita força no texto da peça. Os diálogos parecem carregados de significados e questões a serem elaboradas, desde aquelas relacionadas ao conhecimento, quanto à posição individual de cada um, até as que dizem respeito ao poder e à importância do saber, o qual configura um momento muito importante para o processo.

Além das que foram colocadas, há muitas outras questões que podem ser flexionadas a partir do texto. Uma delas está camuflada mas não deixa de ser um ponto central: colocada por Brecht na figura de Galileu, é a discussão do objetivo do processo 
didático, de proteger as pessoas da alienação e levar a informação, de fato, àqueles que não a têm. Exemplo disso é o fato de que Galileu se relaciona com Andrea, o filho da governanta, e quer ensiná-lo a todo custo ao mesmo tempo em que não se esforça para levar a verdade àqueles que já se conformaram, ou que já passaram por um processo de alienação, aquele com o qual Brecht quer romper:

Galileu - Eu não estou falando de esperteza. Eu sei que na hora de vender o povo chama o burro de cavalo, e chama o cavalo de burro na hora de comprar. Essa é a sua esperteza. A velhinha sabida, que dá mais capim à sua mula porque na manhã seguinte vai viajar; o navegador que provê seu barco pensando na tempestade e na calmaria; a criança que bota um boné se lhe provaram que pode chover, são esses a minha esperança. Eles usam a cabeça. Sim senhor, eu acredito na força suave da razão. A longo prazo, os homens não the resistem, não aguentam. Ninguém se cala indefinidamenteGalileu deixa cair uma pedra de sua mão -, se eu disser que a pedra que caiu não caiu. Não há homem capaz disso. A sedução do argumento é grande demais. Ela vence a maioria, todos, a longo prazo. Pensar é um dos maiores prazeres da raça humana. (BRECHT, 1999, p.81)

Essas são algumas das questões que permitem perceber o quanto a peça Vida de Galileu está repleta de elementos interessantes para um processo como esse, educativo. A discussão, como já dito anteriormente, pode servir de sustentação para um jogo com a prática. Nesse jogo, alguns alunos podem brincar de ser Galileu e outros de ser a Igreja, por exemplo, criando improvisações a partir do texto. Após essas improvisações a discussão continua. Pode-se discutir acerca do que foi falado anteriormente e do que foi colocado em cena. Dessa forma, temos um caminho vasto a percorrer se quisermos colher bons frutos desta relação arriscada, mas que muito pode oferecer. Que o jogo seja divertido!

\section{Considerações finais}

Durante o curso de Licenciatura em Filosofia, a questão do ensino de Filosofia, por enfrentar tantos problemas quanto à sua aceitação e à sua execução nos moldes do ensino atual, nos fez refletir e tentar procurar meios e formas para chegar aos alunos com o intuito de conseguir tirá-los de um "sono profundo" (no qual foram colocados 
por um sistema alienador), para olharem o mundo em que vivem (o qual não estão acostumados a olhar) e descobrirem formas para pensar acerca desse mundo. Uma tarefa difícil, mas que ao mesmo tempo, por ser problemática, nos instiga a pensar, nos faz revirar aquilo que está posto e buscar novas saídas - o que já é algo transformador em sua medida. É claro que todas essas reflexões teóricas farão mais sentido quando forem vivenciadas pela e na prática, mas, por enquanto, é preciso se pensar muito ainda.

Não obstante, neste ainda pequeno caminho que percorremos, pudemos perceber que a proposta de se realizar um processo de união entre Filosofia e Teatro é algo embrionário no sentido prático, requerendo mais reflexões e, principalmente, mais investigações e experimentações práticas. Trata-se de algo que vem sendo explorado através do Teatro Didático, mas que, com a Filosofia, ao mesmo tempo em que fica mais complexo, abre também mais possibilidades para se desenvolver.

Desse modo, este foi um trabalho que temos consciência de que, na sua elaboração, conseguiu responder a algumas questões mais emergentes, que fervilhavam já havia algum tempo. Ao mesmo tempo, como em todo processo ligado à Filosofia, ele também abriu um leque de outras problemáticas que já se podem vislumbrar, mas que foram deixadas "no ar" propositalmente para futuros trabalhos e reflexões nesse campo. Não se tratou de estabelecer um método de ensino (não tínhamos essa pretensão) e por isso o uso frequente da palavra processo, porque o que quisemos começar a vislumbrar foi uma possibilidade para um processo que tem um tempo de duração e metas a seguir, uma das quais consiste em pensar na Filosofia usando o Teatro e vice-versa.

Então, como discípulos que somos de Galileu e Brecht, queremos continuar pela causa (que é social) cada vez mais a buscar o diálogo entre partes opostas - ou não - do conhecimento, com o objetivo de possibilitar aos alunos, aos professores e à sociedade o acesso ao que lhes diz respeito: aprender a pensar e construir uma consciência. Investigar quem somos e para o que somos. Entender as relações com os outros e o com mundo em que vivemos. Isso é algo que deve ser construído pela Filosofia e pelo Teatro, na medida em que lhes cabe fazê-lo. Deve ser dado às pessoas o direito de 
escolher. Mas que essa escolha seja consciente e não preestabelecida por outrem. Essa é a nossa escolha. Escolhemos a vida, a Filosofia e o Teatro.

\section{Referências bibliográficas}

ANATOL, R. Teatro Moderno. São Paulo: Perspectiva, 2005.

BADER, Wolfgang (coord.). Brecht no Brasil: experiências e influências. Rio de Janeiro/São Paulo: Paz e Terra, 1987.

BENJAMIN, W. Tentativas sobre Brecht. Iluminaciones III, Madrid: Taurus, 1975.

.Obras Escolhidas. Magia e Técnica, Arte e Política. Vol.1, São Paulo: Brasiliense, 1994.

BERTHOLD, M. História Mundial do Teatro. São Paulo: Perspectiva, 2006.

BOAL, A. Jogos para atores e não-atores. Rio de Janeiro: Civilização Brasileira, 2002.

BORNHEIM, A. G. Brecht: a estética do teatro. São Paulo: Graal, 1987.

BRECHT, B. Estudos sobre teatro. Rio de Janeiro: Nova Fronteira, 2005.

. Vida de Galileu. Trad. Roberto Schwarz. In: . Teatro Completo v. 6. 3. ed.

Rio de Janeiro: Paz e Terra, 1999, p. 51-170. . Poemas (1913-1956). São Paulo: 34, 2000.

CERLETTI, A. O ensino de filosofia como problema filosófico. Belo Horizonte: Autêntica, 2009.

KOUDELA, I.D. Brecht: um jogo de Aprendizagem. São Paulo: Perspectiva, 2007.

WILLET, J. O Teatro de Brecht. Trad. Álvaro Cabral. Rio de Janeiro: Zahar, 1967. 